\title{
Identidades ambiguas. Movilidad social y conflictos en los Andes, siglo XVII
}

\author{
Ana María Lorandi \\ Facultad de Filosofía y Letras \\ Universidad de Buenos Aires \\ Consejo Nacional de Investigaciones Científicas \\ y Técnicas (CONICET). Buenos Aires
}

El trabajo aborda el proceso de complicación de la estructura de la población global en los Andes durante el siglo XVII, provocada por la movilidad social y aumento de la cantidad de niveles jerárquicos en cada uno de los sectores. Se analiza de qué manera importantes segmentos de población buscan crear sus propios espacios dentro de la estructura global y las disputas entre los miembros, las alianzas sectoriales y/o coyunturales provocan distintos tipos de conflictos en un siglo que hasta ahora ha sido considerado como el siglo donde tuvo un relativo éxito el llamado "pacto colonial". Se señala la existencia de conflictos a causa de la explotación colonial del indígena, pero también aquellos que se suscitan entre agentes del sector español que buscan alianzas muy diversas y que son emergentes de la gran movilidad social.

\section{Planteamiento del problema}

El siglo XVII encierra en su seno todos los síntomas del desarrollo de la colonización, pero también todos los de su disolución. En él están presentes la totalidad de los actores sociales que tendrán pleno protagonismo en la colonia, y las relaciones que se entablan entre ellos reflejan un amplio abanico de situaciones, que van desde las más cerradas lealtades y alianzas hasta los conflictos abiertos y envueltos en violencia. Conflictos, en sus diversas versiones, que reflejan el descontento por la coerción colonial en el caso de los indígenas, pero también, entre los residentes de origen español por la dependencia de un poder extracontinental, a lo que se suma la lucha de los individuos y/o grupos por la obtención de los recursos económicos y la conquista de los espacios sociales y de poder.

Para comenzar debemos considerar las relaciones entre indios y europeos y entre cada uno de estos grandes segmentos de la población con la Corona. Pero si nos detuviésemos aquí el esquema sería muy simple porque reproduce el ideal binario que intentó establecer el virrey Francisco de Toledo al organizar las repúblicas de indios y de españoles. Por lo tanto, 
conviene arrojar una mirada a la composición social del Perú en esa época, que se destaca por el número creciente de niveles de diferenciación social, la emergencia de nuevas categorías de actores, como los mestizos y los criollos, la movilidad entre estos niveles y aún los cambios de identidad y las formas de representación de esas identidades en relación con las prácticas concretas dentro del contexto colonial.

El proyecto toledano en algún sentido reproduce el esquema que la teología católica acepta por esos años para clasificar a la humanidad. El mundo estaba dividido entre ricos y pobres y ese era el designio de Dios. A cada individuo Dios le había asignado una plaza y cada uno tenía la obligación de responder a los deberes de su estado social. ${ }^{1}$ La equidad divina proveía a cada uno de lo necesario a su condición y las diferencias así establecidas garantizaban que los ricos y poderosos gobernasen y los pobres obedecieran. De esa manera el orden social se encontraba asegurado. Este esquema binario entró en crisis cuando en Europa emerge la burguesía, que no tenía un espacio claramente definido. Para colmo esta burguesía cuestiona el orden divino aceptado tanto por jansenistas como por jesuitas, o en términos más generales, rigoristas y probabilistas, las dos principales corrientes del pensamiento teológico y moral del siglo XVII. Jansenistas y jesuitas fueron construyendo distintos tipos de respuestas para enfrentar ese proceso de complicación social, pero esto no disminuía la importancia del desconcierto inicial. Un proceso semejante se desarrolla en América en general, y en el mundo andino en particular en lo que respecta a la relación entre españoles dominantes e indios sometidos, los que por serlo, ocupan el lugar inferior de la escala social. Se los considera, en el mejor de los casos, como niños que deben ser lentamente incorporados a la civilización y por lo tanto necesitan del patronazgo de los nuevos dueños de la tierra, o sea, de sus conquistadores.

Sin embargo, esta bipolaridad se revela irreal a poco de andar. El espacio ultramarino se fue poblando de nuevos agentes de distinta condición social; además, nuevos y viejos agentes renovaban constantemente las formas de vinculación entre ellos y con el aparato burocrático de control colonial. La oscilante y superpuesta legislación de Indias refleja esos vaivenes, corre detrás de las nuevas prácticas que se implementan cada día, tratando de no perder el control, pero el pesado aparato burocrático y jurídico siem-

1 Groethuysen, Bernhard: La formación de la conciencia burguesa, México, (1. a ed. 1927) 1943. 
pre deja resquicios, y muchos, para burlar los principios y la aplicación del cuerpo legal.

\section{Los indios}

En el amplio espacio del virreinato del Perú, el panorama de la población indígena puede ser clasificado como de multietnicidad, multilingüismo y multiculturalismo. Tampoco pueden ignorarse las jerarquizaciones internas de estos grupos, que se fueron reconstruyendo bajo las circunstancias de la colonización, ni la existencia de una élite de ascendencia real incaica que conservaba privilegios y poder simbólico, aunque no efectivo, pero que continuaba siendo vigilada por las autoridades y que era buscada por muchos disidentes para entablar alianzas con ellos, tras el utópico ideal de emancipación o de restauración del antiguo imperio.

\section{Los españoles}

La república de españoles imaginada por Toledo no parece haber contemplado las diferencias internas en este estrato social. Por lo menos no con la variedad de escalones que se fueron abriendo a lo largo del tiempo. En el documento elaborado por los comisarios reales de la perpetuidad de la encomienda y sus asesores locales en la década de $1560-70,{ }^{2}$ se expresa la necesidad de que se mantenga un flujo constante de nuevos españoles para evitar que los de residencia más antigua, o sus hijos, se fueran desvinculando de España y de sus orígenes. Vieron con gran clarividencia los peligros de emancipación que entrañaba esta desvinculación, argumentación que se renueva en el siglo XVII. ${ }^{3}$

Ahora bien, la migración continua fue creando diferencias y mecanismos de inclusión y exclusión que provocaban un aumento de los estratos internos del estamento de origen europeo. Los nuevos inmigrantes debían

2 "Carta de los Comisarios a S.M. sobre la perpetuidad y otras cosas", en Nueva Colección de Documentos Inéditos para la Historia de España y de sus Indias, publicada por Francisco de Zabálburu y José Sancho Rayón, tomo VI, Madrid, 1896, págs. 47-268. Esta carta no tiene fecha, como lo confirma una nota de los editores, pero debió ser escrita en 1562 por a una referencia a 1561 que se hace al comienzo.

3 Glave, Luis Miguel: De Rosa y espinas. Economía, sociedad y mentalidades andinas, siglo XVII, Lima, 1998. pág. 64. 
buscar un lugar en el espectro colonial. Lockhart distingue en primer lugar a los ya instalados y luego a aquéllos que venían como parte de las redes familiares, "los sobrinos", o los paisanos, ${ }^{4}$ que llegaban con una base firme para iniciar sus nuevas vidas en la colonia, en un movimiento de inclusión que a lo largo del tiempo podía producir desprendimientos y procesos paralelos de exclusión. Lockhart los diferencia de aquellos otros que carecían de apoyos locales y que debieron ocupar un lugar netamente marginal dentro de la estructura social y económica. Se debe considerar, por lo tanto, la proximidad del parentesco, las condiciones familiares y, para el caso de las sucesivas oleadas de inmigrantes, las oportunidades existentes en el momento de su llegada, las coyunturas políticas y, sin duda, la capacidad de los individuos para introducirse en las redes económico-sociales, o para iniciar nuevas aventuras de conquista, si los espacios disponibles no se correspondían con sus aspiraciones y expectativas.

En los escalones más bajos de la jerarquía se encontraban muchos de éstos últimos que se desplazaban entre las ciudades y haciendas buscando oportunidades y a quienes las autoridades denominaron "vagabundos". Se consideraba que era sumamente peligroso que hubiese personas sin status claro y sin funciones específicas. Conviene preguntarse, entonces, cuáles eran las razones de tanta alarma en términos del "interés general". La respuesta está en los mismos documentos de la época, porque una persona que no lograba adaptarse al sistema podía querer alterarlo u obtener el rango al que aspiraba por medios subversivos. Es el caso, como veremos, de Pedro Bohorques, que era uno de esos españoles marginales. Como lo señalaba el virrey príncipe de Esquilache a principios del siglo XVII, estos individuos podían entablar alianzas peligrosas y provocar sediciones. Lo que he llamado las alianzas "espurias" fueron siempre consideradas como extremadamente perniciosas para la salud política de los reinos de ultramar.

\section{Los criollos}

Aunque éstos se consideraron españoles de pleno derecho debieron soportar, con demasiada frecuencia, que se obstaculizaran sus aspiraciones a participar en los puestos más altos de las jerarquías estatales. Las rivalidades entre criollos y peninsulares provocaron no pocos conflictos, incluso en las

4 Lockhart, James: “Organización y cambio social en la América española colonial”, en L. Bethell (ed.), Historia de América Latina, Barcelona, 1990. 
órdenes religiosas, como ha demostrado Bernard Lavallé en numerosos trabajos. ${ }^{5}$ La mayoría de los criollos jamás viajaron a la Península, y fueron construyendo un conjunto de representaciones sociales y políticas hechas a la medida de sus vidas cotidianas en estos reinos de ultramar. Las realidades cotidianas y los intereses personales y familiares se priorizaron frente al interés metropolitano. Se fue constituyendo así una conciencia más ligada a la residencia que al origen familiar. Por supuesto esto debe ser considerado con extrema prudencia y con variados matices, porque depende de la personalidad, del self que cada historia de vida haya modelado en los individuos.

A medida que el tiempo transcurría, el problema del criollismo fue tomando un cariz más crítico. Sucesivas generaciones de criollos fueron poblando los amplios territorios, muchos de conquista más reciente, y adquiriendo posiciones políticas de relevancia. La distancia ideológica con la metrópolis aumentaba a medida que aumentaba la cantidad de generaciones. Sin embargo, este proceso encontró sus límites en los matrimonios con los "españoles nuevos", que además podían aportar capital fresco que revitalizaba las alicaídas economías familiares de antigua raigambre local. En este sentido, las recomendaciones del informe de los comisarios de la perpetuidad, a las que ya aludimos, se cumplieron en buena medida. Las nuevas oleadas de inmigrantes renovaban los vínculos con la metrópolis impidiendo un desgajamiento prematuro. No obstante, el proceso de consolidación de los criollos en las capas intermedias y semi-altas de la burocracia estatal se afirma en este maduro siglo XVII.

\section{Los mestizos}

El primer resultado del "encuentro" de españoles y naturales culmina en la aparición del mestizo. Hay escasa legislación para ellos. Tan solo algunos intentos de limitarles los espacios sociales en los que pueden cir-

5 La "alternancia o alternativa" en el gobierno de las órdenes religiosas consistía en que en la elección de sus autoridades debían rotar alternativamente un peninsular y un criollo. Esta fue la solución encontrada para evitar que los criollos, muy superiores en número, hegemonizaran el gobierno de las órdenes. Lavallé, Bernard: “Del 'espíritu colonial' a la reivindicación criolla o los albores del criollismo peruano". Histórica, II (1), Lima, 1978, págs. 39-61; "Planteamientos lascasianos y reivindicación criolla en el siglo XVII". Histórica, IV (2), Lima, 1980, págs. 197-220; Recherches sur l'apparition de la conscience créole dans la Vice-Royauté du Pérou. L'antagonismo hispano-créole dans les Ordres Religieux (XVIe-XVIIe siècles), Tesis, Université de Bordeaux, III (inédita). Atelier National de Reproduction des Thèses, Université de Lille, III, 1982; "La admisión de los americanos en la Compañía de Jesús: el caso de la Provincia peruana en el siglo XVI”, Histórica, 9 (2), Lima, 1985, págs. 137-154, y Las Promesas Ambiguas. Criollismo Colonial en los Andes, Lima, 1993. 
cular. Pero la variedad de situaciones en las que nacen y viven estos mestizos hace casi imposible fijarlos en un espacio acotado claramente definido. Todos sabemos que los hijos mestizos de los primeros conquistadores y encomenderos fueron en muchas ocasiones sus herederos legítimos y que con el tiempo se fue borrando todo estigma social. El proceso de mestizaje no se detuvo nunca, y la condición social del mestizo dependía fundamentalmente del espacio que su padre le otorgase y de las circunstancias específicas de su nacimiento. Si los hijos quedaban viviendo en las comunidades de sus madres, podían ser considerados incluso tributarios, o sea que eran asimilados al origen materno. Si las uniones se realizaban entre hidalgos o encomenderos con mujeres del servicio doméstico, el lugar que se reservaba al hijo dependía del afecto que el padre sintiera por él o de la situación general en la que se encontraba el padre en el seno de su familia legítima. Pudo ser reconocido, o no serlo; ${ }^{6}$ pudo recibir una parte de herencia, aunque fuera por donación especial; o quedar relegado a la condición de criado doméstico. Cada caso tiene una resolución particular y, cuando un mismo padre tuvo varios hijos mestizos, cada uno de ellos quedó sujeto a un destino diferente.

En una posición intermedia se encontraban los mestizos producto de uniones de españoles pobres o de condición subalterna. Estas situaciones eran más frecuentes en el medio urbano y los hijos de estas uniones tendrán espacios en los servicios, el comercio y las artesanías. En el medio rural estarán especialmente ligados a la hacienda, pero también a la minería. La condición de los mestizos está siendo revisada últimamente por Nicanor Domínguez a la luz de estas variables "situacionales" e históricas. ${ }^{7}$ Destaca que este mestizaje histórico-cultural comienza desde el momento en que se produce el desarraigo de los indios de sus comunidades de origen. Según los casos, abandonan los signos específicos de su vestimenta y tratan de mimetizarse con los españoles. Adoptan oficios urbanos, o por el solo hecho de contratarse libremente, con jornales previamente pactados con los mineros que no recibían servicio de mitas, pudieron cambiar su condición fiscal y en algunos casos desprenderse de su adscripción étnica. Más allá del indudable proceso de mixtión, el mestizo es un producto cultural.

6 Boixadós, Roxana: “Transmisión de bienes en familias de élite. Los mayorazgos de La Rioja colonial”, Andes, 10, Facultad de Humanidades, Universidad Nacional de Salta, 1998.

7 Domínguez, Nicanor: "Mestizo, Rebels against the King in the colonial Andes: 1660s Laicacota Rebelion (Puno, Perú), Proposal for Dissertation Research. (ms.) 1998; "The Laicacota crisis of mid-seventeenth colonial Peru", (ms) 1998. 


\section{El trasfondo de los conflictos}

Las contradicciones legales, la distancia a la metrópolis, la coacción sobre los indígenas y el flujo constante de interés que enfrentaban a los actores sociales por el control de bienes y recursos, se encuentran entre los factores que causaron las tensiones y los conflictos.

Mi hipótesis es que la heterogeneidad de una sociedad compuesta por tantos segmentos étnicos y diferenciaciones sociales, y tantas historias de vida diferentes, generaron contradicciones insolubles entre sectores e individuos, y favorecieron el clima de permanente inestabilidad y conflicto que distingue al Virreinato

Como consecuencia, el perfil predominante de la sociedad colonial estará dado por la tensión permanente entre la búsqueda de status y poder (incluyendo la opresión sobre los indígenas) y el peligro de la anarquía y la disolución. De ahí que la independencia, que se gesta tan tempranamente en la historia colonial, tarde tres siglos en ver la luz. Por eso también se considera que el siglo XVII fue un siglo de paz. Al observar los conflictos locales o reducir la escala del análisis, siguiendo los principios de la microhistoria, se pueden observar las disputas que se manifiestan en los distintos campos sociales. ${ }^{8}$

\section{Los conflictos en el siglo XVII}

Por cierto que los conflictos aparecieron muy pronto en el virreinato del Perú (entre 1535-1548), sobre todo por las cruentas guerras civiles. Es un error considerar que las causas que provocaron estos enfrentamientos simplemente desaparecieron del mapa regional con el orden impuesto por Toledo. Por el contrario, continuaron latentes, y cualquier detonante era bueno para justificar alguna forma de resistencia, activa o pasiva. Puedo sintetizar diciendo que en ese caldo de cultivo de las contradicciones se pueden observar diversos tipos de síntomas que se revelaron a partir de conductas desviadas o intolerables para las autoridades, o bien, directamente en conflictos abiertos.

8 Revel, Jacques: "Micro-análisis y construcción de los social". Anuario del IEHS, 10, Tandil, Buenos Aires, 1995, págs. 125-143; Bourdieu, Pierre: Choses dites, Paris, 1987. 


\section{Las alianzas espurias}

En esta categoría incluyo a todas las formas de alianza entre individuos o grupos de origen español y los indígenas, cualquiera que sea la condición de éstos últimos, y que resultaban parcial o totalmente inaceptables para las autoridades coloniales. Como lo explica Luis Miguel Glave, el siglo XVII se despierta con síntomas de levantamientos de este tipo. Unos meses antes, en abril de 1599, el relator Juan Díaz de Ortiz, aliado con otros españoles (¿o criollos?) $)^{9}$ prepara un motín con el objetivo de alzarse con la Hacienda del Rey y de otros particulares que bajaba hacia Arica para ser enviada a España. Ortíz ya había tenido actuación en Cochabamba protegiendo a los indios contra diversos abusos. Aunque trataron de hacer pasar este caso como un simple hecho delictivo, es evidente que una determinación tan drástica como alzarse con las cajas reales debía tener un propósito de más largo alcance.

El otro caso documentado por Glave en la obra citada es el de don García de Solís Portocarrero que fue ejecutado en la ciudad de Huamanga, acusado de complot contra el Rey, en alianza con Melchor Carlos Inga, a quien se le permitió pasar a España. Pero García y un cómplice fueron ajusticiados en 1601. La idea de restaurar el Imperio del Sol no era nueva en este siglo. Fray Francisco de la Cruz fue ejecutado por el virrey Toledo en 1578 bajo la misma acusación. Y no es el único antecedente.

Como lo desarrolla en detalle David Brading en Orbe Indiano ${ }^{10}$ muchos religiosos en sus crónicas y memoriales hicieron una encendida apología de los indios, criticaron duramente los abusos a los que les sometían los españoles y defendieron el derecho de los criollos a ocupar cargos de importancia en la burocracia de los reinos americanos. Sin embargo, Brading no deja de observar las contradicciones en las que a veces incurrían esos mismos autores al elogiar a la vez a los incas y a sus conquistadores. Entre ellos se encuentran, por ejemplo, el agustino Antonio de la Calancha y el franciscano fray Buenaventura de Salinas y Córdoba, a quien Santisteban Ochoa titula como un "precursor de la Independencia en el siglo XVII"."

9 Glave: De Rosa y espinas..., págs. 63-68.

10 Brading, David: El Orbe Indiano. De la monarquía católica a la república criolla, 1492-1867, México, 1991.

11 Lima 305. Cuzco 1636. Citada por Santisteban Ochoa: "Documentos para la historia del Cuzco", Revista del Archivo Histórico del Cuzco, 2, Cuzco, 1963, págs 21-23. 
Otros casos fueron la búsqueda directa de alianzas con los caciques o con los restos de incas refugiados en la selva, que ilustraremos con las gestas del andaluz Pedro Bohorques, ${ }^{12} \mathrm{o}$ del mestizo Ramírez Carlos.

Las aventuras del artesano mestizo Diego Ramírez Carlos son menos conocidas y merecen un párrafo más extenso. Los hechos se desarrollan en la década de 1620. Hay dos versiones sobre los sucesos que involucran a este personaje. La del propio actor, que trata de hacer valer sus méritos en la conversión de los infieles, y la del fraile franciscano Gregorio de Bolívar que participa de las "entradas" a los chunchos junto con Ramírez Carlos y que intenta, a su vez, borrar los efectos de lo que pudo ser, de alguna manera, otro caso de "alianza espuria". El Memorial y Relación del padre Bolívar resume los hechos sustanciales de este caso. ${ }^{13}$ Contiene además una extensa y muy detallada descripción geográfico-etnográfica de la región de los chunchos.

Según fray Gregorio Bolívar, había conocido a Ramírez Carlos en La Plata. Era un "oficial de labrar arpas y guitarras" y parece haber sido un músico excelente, con especiales dotes de seducción. ${ }^{14}$ En 1620 Ramírez Carlos visita a Bolívar en La Paz, porque conocía su interés por la conversión de los chunchos, y le invita a buscar un grupo de incas refugiados en la selva que podrían ayudarles en la evangelización de los infieles. Le expresa que éstos están dispuestos a aceptar la nueva religión y la autoridad del Rey. Con provisión favorable del virrey, el fraile acepta acompañarle en esta aventura. Pero pronto asoman desacuerdos entre ambos, en particular cuando no pueden encontrar a los supuestos incas y Ramírez Carlos se muestra incapaz de señalar un rumbo certero para localizarlos. El segundo inconveniente se produce cuando fray Gregorio descubre que su compañero dice ser hijo de Melchor Carlos Inca, nieto a su vez de Paullo Inca y bisnieto de Wayna Cápac. Ramírez Carlos hace anunciar su llegada a los pueblos por un sirviente mulato que tocaba un clarín y se hace venerar como Inca, para lo cual estaba provisto de las vestimentas que así lo representan. ${ }^{15}$ Bolívar trataba a veces de desenmascararlo, pero Ramírez reaccionaba diciendo que el fraile quería que entrasen españoles para escla-

12 Lorandi, Ana María: De Quimeras, rebeliones y utopías. La gesta del Inca Bohorques, Lima, 1997.

13 Archivo General de Indias (AGI), Lima 41, n. ${ }^{\circ}$ 58, 27 de febrero de 1628.

14 Ibídem. Según el fraile, Diego Ramírez Carlos era hijo de una mestiza del pueblo de Colquemarca en territorio de los Carangas y de un cierto clérigo llamado "fulano" Ramírez.

15 Ibídem. En una ocasión Ramírez Carlos le regaló a un cacique un traje inca de cumbi (telas muy finas, usados solo por determinados personajes y en ceremonias). 
vizarlos y que sólo él decía la verdad; que traía la conversión pero que no serían sometidos ni obligados a trabajar para los españoles. Nunca aclara sus verdaderas intenciones, pero en las entrelíneas del relato del fraile Bolívar se puede leer que Ramírez propiciaba la formación de un Estado cristiano pero independiente del gobierno de los españoles.

Así pasó más de un año entre disputas e intrigas, sin que el padre Bolívar lograra verdaderas conversiones y sin que aparecieran los supuestos incas refugiados. Al final, convencieron a unos indios para que fuesen a la ciudad de La Paz con el propósito de que conociesen la forma de vida españolas, quedando fray Gregorio Bolívar como rehén hasta que regresaran. Ramírez Carlos, que acompañaba a la misión que subía a la sierra, los presenta como caciques y principales de grandes señoríos, que venían a dar la paz y obediencia al Rey, por lo cual las autoridades civiles y eclesiásticas de La Paz los recibieron con toda pompa y deferencia. El franciscano negará después que se tratase de caciques, admitiendo tan sólo que eran indios del común que exploraban las posibilidades de iniciar "rescates" con los pueblos de españoles. De regreso a la selva Ramírez Carlos vuelve a reunirse con el religioso quien, mientras tanto, había entablado sus propias relaciones, no siempre del todo cordiales, con los indios. Ramírez se "amanceba" con la hija de un cacique, quien le autoriza a que un hijo suyo le acompañe hasta Lima, donde solicita apoyo del virrey. Sale de la selva llevando cartas del fraile que nunca entrega e intriga en cambio en su propio favor. En determinado momento, Bolívar regresa e inicia tentativas para que la conversión la continuasen otras órdenes, pero en definitiva nada se hace. Ramírez Carlos aparentemente se había instalado en Potosí, "aunque pocos días ha me dijeron que era muerto" dice fray Gregorio; o sea poco antes de 1628, que es la fecha de su Memorial y Relación.

La contra-versión de esta historia, en el testimonio de Diego Ramírez Carlos, oculta expresamente toda relación de su persona con la monarquía incaica ${ }^{16}$ Por el contrario, relata que hizo esta entrada, que fue bien recibido por los indios y que expresaron su conformidad de aceptar la autoridad real, siempre que no se les obligase a servicio personal "ni otro encomendero sino la real Persona de Su Magestad". Ramírez Carlos le dice al Rey que Bolívar va cumpliendo su misión y que entre ambos consiguieron que caciques y gobernadores de muchos e importantes pueblos fueran a dar su obediencia a La Paz. Le da cuenta al Rey de que el virrey príncipe de

16 AGI, Lima 151. Carta de Diego Ramírez Carlos al Rey. 1621-1626. La cita textual, en fol. 1. 
Esquilache, que estaba para regresar a España y llevaría su carta, había sido padrino de bautismo del hijo del cacique que le había acompañado. Por todo ello pide mercedes y ayuda porque hasta el momento todo lo había hecho a costa de su propia hacienda. Es evidente que Ramírez Carlos no logra el apoyo que esperaba y no hace nuevas entradas, o al menos no he encontrado constancia de ello.

El caso de Pedro Bohorques será expuesto muy brevemente, dado que recientemente he publicado un libro sobre este personaje. ${ }^{17}$ De origen andaluz, llega al Perú hacia el año 1620 y se casa con la hija de un mulato y de una indígena, yendo a vivir a la comunidad de la madre de su esposa. Es el típico personaje vagabundo y desclasado sobre quien alertaban los virreyes Luis de Velasco en 1601 y el príncipe de Esquilache en 1618, y que lo coloca en un lugar de sospecha a los ojos de sus compatriotas. Años después (en la década de 1630) emprende largos recorridos por la sierra, informándose sobre dos tópicos esenciales que otorgan sentido a sus acciones posteriores: por un lado los mitos de Inkarrí y los debates jurídicos de los nobles incas para conservar sus preeminencias en la colonia, sumado a la historia de los reyes incas en tiempos prehispánicos, y por el otro recoge los mitos sobre el Dorado, en particular el Paytiti, localizado entre otros lugares en los llanos de Moxos en Bolivia. Sus aspiraciones de ascenso social y de heroicidad medieval como vehículo para obtener su anhelado espacio de privilegio, sumados a una personalidad fabuladora, pero a la vez capaz de asumir los riesgos de la aventura, lo impulsan a buscar el Paytiti mediante diversas entradas a la selva, asumiendo el rol de descendiente de los incas. Durante la última de estas entradas, en 1649-50, para la que finalmente cuenta con una autorización oficial, tiene por objetivo más inmediato el descubrimiento del Cerro de la Sal. Se introduce en las misiones dominicas en la región de Quimiri, al Este de Tarma, y asegura que fundó una ciudad gobernada por un cabildo integrado por los hombres de su hueste, y que ha repartido tierras que pobló con ganado. Ganado robado en las estancias de la frontera de Tarma lo que provocó la reacción de las autoridades y su apresamiento. En este episodio se puede observar el sincretismo que asume Bohorques: la unión de un antiguo imperio con los privilegios de un conquistador, colonizador y fundador de ciudades. El memorial que da cuenta de esta historia revela la intención preformativa de su discurso. Asegurando haber encontrado un reino fabuloso, se convence a sí mismo de que éste existe e

17 Lorandi: De Quimera, rebeliones y utopías... 
informando sobre sus conquistas y fundaciones se ve a sí mismo con los atributos y destinos reservados a los grandes de la colonia. El espacio simbólico que construyen estas alianzas "espurias" alienta a la aventura; no importa cuán terribles sean los peligros físicos, políticos o sociales que se deban enfrentar.

Enviado al fuerte de Valdivia chileno, cumple seis años de prisión y luego huye hacia los valles Calchaquíes. Valles que conservaban aún su autonomía a mediados del siglo XVII a pesar de los reiterados pero infructuosos esfuerzos de las autoridades provinciales por conquistarlos. En el trayecto se aloja en las estancias criollas contando sus aventuras y mostrando un mapa del Paytiti que, según su relato, había dejado bajo el gobierno de uno de sus hijos. Promete riquezas y logra conquistar, con su indudable carisma, las voluntades de quienes le hospedan. Una vez en el valle Calchaquí es recibido como rey Inca, y ocupa el vacante liderazgo de la resistencia que sus pobladores han sostenido con éxito durante más de un siglo. Su estrategia consiste en negociar con el gobernador del Tucumán, don Alonso Mercado y Villacorta, prometiendo que su nuevo estatus le permitirá obtener los secretos sobre minas y tesoros que los indígenas ocultan celosamente y que en el imaginario local son las causas de tan enconada y prolongada resistencia. Bohorques y el gobernador acuerdan un encuentro en un lugar neutral, fuera del valle, en un pueblo llamado Pomán. El gobernador invita a participar en esta reunión a los vecinos más notables de La Rioja y Catamarca y Bohorques llega acompañado de los caciques del valle Calchaquí. Durante el encuentro se alternan las reuniones con las fiestas, creando un clima de solemnidad farandulesca para escenificar el drama que allí todos representan. Bohorques obtiene el nombramiento de capitán general y justicia mayor para imponer su autoridad en los valles rebeldes y por otro lado una formal autorización para utilizar el título de Inca. Se le otorga una extensa jurisdicción para que, bajo su prestigio de Inca, pueda descubrir las minas incluso de fuera del valle. A cambio promete también impedir que en lo sucesivo el valle Calchaquí continúe siendo un área de refugio para los que escapaban de las encomiendas. Con su autoridad debe convencer a los indios para que cumpliesen con las mitas a sus encomenderos y con ayuda de los padres de las dos misiones jesuitas que habían logrado instalarse en el valle, colaborar con su conquista definitiva por medios pacíficos.

Al conocer estos acuerdos, el virrey desautorizó al gobernador ordenándole con severidad que apresase a Bohorques, reprochándole que le hu- 
biese permitido fuese considerado como Inca. Este era el principal argumento del virrey, que no admitía que hubiese negociado la conquista de los rebeldes calchalquíes por un camino tan "torcido".

Bohorques permaneció en la región durante casi dos años, durante los cuales hubo un permanente juego del ratón y el gato con el gobernador, que no acertó a encontrar el medio de eliminarlo. La tensión creció en la región y los preparativos de ataque culminaron con un combate en el que Bohorques y sus indios fueron derrotados, tras lo cual y por exigencia del sedicioso, un oidor de la Audiencia de Charcas se desplazaron hasta el Tucumán para negociar su rendición y traslado a Lima. Ambas cosas se efectuaron en 1659, bajo la promesa de un indulto general que luego las autoridades no respetaron. Al llegar a Lima fue encarcelado y se inició un largo proceso. Casi ocho años después, en enero de 1667, fue ejecutado bajo la acusación de conspiración con los curacas de la región de Lima para provocar una gran rebelión, cuyas particularidades expondremos más adelante.

Podemos ver el caso de Bohorques a través de la óptica de la época, expresada en las palabras del historiador jesuita Pedro Lozano:

\begin{abstract}
“Así terminó la pertinacia de este hombre, que aspiró ambicioso a no menor empresa que la de coronarse rey de las Indias. Este paradero tuvieron sus raras astucias y marañas, dirigidas todas al valer más, y ser más, pero erró el medio que fue fingirse indio cuando los indios son en Indias los que menos valen. ¡Raro capricho el de este hombre!". ${ }^{18}$
\end{abstract}

Estoy convencida de que a medida que el tiempo transcurría, Pedro Bohorques se fue consustanciando cada vez más con los objetivos y principios de liberación del indígena, que incorporaba a su discurso. En el último período asume totalmente la causa de los indios y se juega la vida por ellos. Las palabras del virrey Alba de Liste son muy ilustrativas del sentimiento de los españoles hacia este tipo de alianzas "espurias". Dice que Bohorques es un hombre "que no tiene lugar en el mundo".

Para completar los comentarios sobre este tipo de relaciones "espurias", quiero destacar los interesantes datos que Miguel Glave aporta en su último libro, acerca de muchos agentes españoles que entablaron alianzas con los indígenas o que apoyaron sus pretensiones políticas y podrían ser incluidas bajo el mencionado título. Son esos pequeños datos, que se mul-

18 Lozano, Pedro, S. J.: Historia de la Conquista del Paraguay, el Río de la Plata y el Tucumán, Buenos Aires, 1784-1785, pág. 176. 
tiplican en la literatura acerca de todas las regiones del virreinato, los que muestran las contradicciones del sistema, porque estos agentes se enfrentan con los intereses y prácticas, muchas veces corruptas, tanto de particulares como de funcionarios. Y esto sin hablar de facción de los grupos familiares y de las redes económicas y las constantes disputas por los espacios de poder que alimentan ese clima de cotidiana inestabilidad social. No los puedo desarrollar por falta de espacio, pero lo quiero destacar especialmente, porque constituyen una clave, a mi criterio, para dibujar un perfil diferente de la situación social del siglo XVII. Un perfil menos complaciente de esa sociedad heterogénea que tiene grandes dificultades para construir su destino.

\section{Los levantamientos indígenas}

En el siglo XVII hubo diversos conatos de levantamientos indígenas a veces con el declarado propósito de matar a todos los españoles para recuperar la autonomía política. En general fueron rápidamente desbaratados, aunque en mi opinión merecerían ser reinvestigados con mayor atención, dentro del planteamiento que he expuesto en el párrafo anterior. Los indios consideran que los abusos de las autoridades, de los encomenderos y en general de los agentes coloniales vulneran constantemente sus derechos y extreman las condiciones de opresión a las que son sometidos. Se defienden con un sinnúmero de estrategias, ya sea con sus conocidas migraciones, creando la categoría de forasteros para escapar de las mitas; ${ }^{19}$ explotando ilegalmente el mineral de las minas; ${ }^{20}$ incorporándose de diversas maneras al mercado; recurriendo a la justicia; escribiendo como Guaman Poma una carta de 500 páginas al Rey, etc. Pero poco a poco estas estrategias no r0esultaron suficientes y al descontento de los indios se comienza a sumar el de otros componentes étnico-sociales que buscan un lugar en la sociedad.

En 1613 se produce la primera conspiración con amplia base regional. En la sublevación se organiza una red de alianzas en las que deberían intervenir grupos de tierras bajas, o sea de chunchos, y grupos de tierras altas.

19 Saignes, Thierry: "Las etnias de Charcas frente al sistema colonial (siglo XVII): ausentismo y fugas en el debate sobre la mano de obra indígena (1595-1665)", en Jahrbusch für Geschichte von Staat, Wirtschaft und Gesellschaft Lateinamerikas, XXI, Köln, 1984.

20 Tandeter, Enrique: Coacción y mercado. La minería de la plata en el Potosí Colonial, 1692-1826, Buenos Aires, 1992. 
Todas las ciudades deberían ser atacadas simultáneamente el día de Corpus Christi. ${ }^{21}$ Empero esta conspiración es desbaratada y el corregidor de La Paz, según Saignes, ordena silenciar todo este asunto. Es probable que la convocatoria a indígenas de tan diferentes estructuras de poder y con un objetivo tan ambicioso haya hecho imposible que finalmente se concretara la rebelión.

En 1623 un alzamiento indígena en Songo (un pueblo de cultivadores de coca en las yungas de La Paz) $)^{22}$ progresa en cuanto a la organización de los indígenas. Exasperados por los abusos a los que son sometidos, matan al corregidor y a varios españoles y mestizos. En este caso, también se establecen alianzas con pueblos del altiplano, como los lupacas de Chucuito y "otros comarcanos". La estrategia es similar a la de la conspiración de diez años antes: matar a los españoles y luego refugiarse en la selva. Los preparativos de la rebelión y la actitud disidente se prolongan por un año. Los sublevados preparan cuevas en los alrededores de La Paz para esconderse y almacenar provisiones y armas. En particular los del Collao debían atrincherarse en un antiguo fuerte en Tiwanaku. Tres frailes franciscanos sirven de enlace y consiguen desarmar la conspiración, que de todas formas culmina con la ejecución de seis caciques, incluido el líder Gabriel Huaynaquile.

En la zona de La Paz la inquietud se renueva en 1644. Se repiten las mismas consignas - matar a los españoles y huir-y las mismas alianzas interétnicas, aunque en este caso llegan a la acción armada matando a un representante del corregidor. Empero, en esta ocasión el propio cacique logra apaciguarlos.

Los indios de Ochusuma y Iruito (grupos del tronco uru; pescadores del lago Titicaca, que a diferencia de otros urus no estaban aymarizados) inician acciones de bandolerismo organizado. Entre 1632-33 atacan varios poblados aymaras, incluso la iglesia de San Andrés de Machaca, donde maltratan imágenes de la Virgen y del Niño Jesús. ${ }^{23}$ Afirman que ellos no eran cristianos y que no obedecerían al Rey. En un primer intento de represión son ejecutados varios de ellos, incluso su jefe. Pero esto no los amila-

21 Saignes, Thierry: "Algún día todo se andará. Los movimientos étnicos en Charcas (siglo XVII)". Revista Andina, año 3 (2), Cusco, 1985, págs. 425-450.

22 Ibídem.

23 Calancha Antonio de la, y Bernardo de Torres: Crónicas agustinas del Perú, Tomo I, Madrid, 1972; Wachtel, Nathan: Le Retour des Ancêtres. Les Indiens Urus de Bolivie, XVIe-XXe siècles. Essai d'histoire régressive, Paris, 1990, pág. 378. 
na; nombran en seguida un sustituto, recuperan las cabezas de los ejecutados y reinician los ataques. Los mismos aymaras intentan reducirlos, apoyados en una ocasión por Juan Recio de León, que comandó 100 balsas de totora aportadas por los pacajes y lupacas y entró "a fuego y pólvora, quemando las islas y reduciendo a los rebeldes que no bajaban de 300", ${ }^{24}$ aunque estos éxitos parciales no anulaban la capacidad de estos urus de organizarse en otras zonas. En un momento los Ochusumas buscan una alianza con otros grupos urus del Titicaca y del Desaguadero e incluso los del lago Poopó. Los ataques a poblados indígenas y el bandolerismo rural se prolongan hasta finales del siglo XVII.

Este caso muestra algunas aristas diferentes. Es la forma menos orgánica de rebelión. El bandolerismo responde a objetivos más inmediatos, menos utópicos. Como lo señalan Aguirre y Walker, ${ }^{25}$ el bandolerismo ha sido interpretado desde diversas versiones teóricas. La más difundida, siguiendo las propuestas de Eric Hobsbawn, considera que estos movimientos o acciones criminales responden directamente a problemas sociales y de clases; es lo que se ha llamado el bandolerismo social. Otra vertiente prefiere explicarlos como delitos comunes de los marginados de la distribución de la riqueza.

Recordemos que los urus eran los marginados de los marginados. Wachtel ha explicado en detalle el proceso de diferenciación interna de los urus a partir de la aymarización de algunos, forzada o voluntaria, y el arrinconamiento de otros en las islas lacustres del Titicaca y del Poopó, que rechazaron su incorporación o mimetización con los aymaras. Lo cierto es que, al ocupar el lugar más bajo en la escala social, son los mismos grupos aymaras, como los pacajes y lupacas, los que los combaten, porque son los más perjudicados. O sea, los urus están atacando predominantemente a sus enemigos sociales más inmediatos, con el único recurso disponible en el estado de marginación en el que se encuentran.

En el centro del Perú se producen también diversos intentos de rebeliones, generalmente abortadas. En abril de 1633, el virrey conde de Santisteban ordena al oidor licenciado don Fernando de Velasco y Gamboa que se dirigiera a la provincia de Cajatambo para intervenir en un levantamiento de los indios del obraje de Churín. Estos se habían rebelado a causa de los malos tratos que se les infería en el obraje. En agosto del mismo año,

24 Glave: De Rosa y espinas..., pág. 95.

25 Aguirre, Carlos y Charles Walker: Bandoleros, abigeos y montoneros. Criminalidad y violencia en el Perú, siglo XVIII-XX, Lima, 1990. 
unos 600 indios armados y con pinturas de guerra atacaron la casa del oidor al grito de "mueran todos los españoles porque la tierra es nuestra". ${ }^{26}$ El oidor salvó a duras penas su vida, pero luego logró reducirlos, ejecutando a ocho de los principales conjurados.

En los últimos meses del 1666 se recibe la denuncia de que se preparaba una gran conjuración de los curacas de Lima unidos a otros de las sierras vecinas y del sur del Perú. La denuncia provenía del gobernador de los indios de la provincia de Cajamarca llamado Diego Lobo, e informaba que “...los de la capital debían alzarse en víspera de Reyes..”. ${ }^{27}$ A causa de rencillas internas entre los conjurados, Lobo los delató al protector de naturales don Diego de León Pinelo. En otras versiones la conspiración es descubierta por comentarios hechos en un velorio, en el que se encontraban varios alcaldes de las parroquias indígenas, donde se afirma que "dentro de pocos días se avían de acabar todos los españoles y avían de quedar solos los yndios porque los avían de matar a todos.... ${ }^{28}$ Por primera vez en el siglo XVII un movimiento indígena se sustenta en el retorno del Inca y en pos de ese objetivo los curacas comienzan a organizarse colectivamente en una actitud ya no reivindicativa sino revolucionaria, puesto que pensaban incendiar Lima, "soltar el agua de la acequia grande de Santa Clara" ${ }^{29}$ y masacrar a los españoles. Ese mismo día hubo tres temblores en Lima donde el líder del movimiento fue Gabriel Manco Cápac, un curaca que había logrado convocar a otras autoridades andinas de la sierra central. La noche del 31 de diciembre se tienen noticias de una concentración de 3.000 indios en la sierra y se envía un destacamento de 300 hombres a desbaratarlos. Se dice que preparan el ataque para la víspera de Reyes, pero no pueden localizar a los conjurados. Manco Cápac logra huir a Jauja donde continúa tejiendo alianzas con los de las provincias de Yauyos y Huarochirí para proseguir la rebelión, preparada para atacar lugares habitados por españoles el día 2 de marzo de $1667 .{ }^{30}$ Este movimiento alerta a las autoridades, que al año siguiente inician una averiguación sobre su extensión

26 Lohmann Villena, Guillermo: El conde de Lemos, Virrey del Perú, Madrid, 1946, pág. 83.

27 Lorente, Sebastián (ed.): Relaciones de los Virreyes y Audiencias que han Gobernado el Perú...I, Memorial y Ordenanzas de D. Francisco de Toledo, Lima, 1867, pág. 186; citado por Lohmann Villena: El conde de Lemos..., pág. 89.

28 Lohmann Villena: El conde de Lemos...

29 Archivo del Consejo Municipal, Huancavelica, Expedientes coloniales, siglo XVII, (ACMHEC) 1f. Pease, Franklin: "Mesianismo andino e identidad étnica: continuidades y problemas", $C$ ultura, V, 13, 57-71, Quito, 1982, pág. 61 y nota 1.

30 Lohmann Villena: El conde de Lemos..., pág. 91; Pease, F.: "Unidades étnicas y noción de identidad en el Perú colonial”, Cielo Abierto, 17: 39-48, Lima, 1981, pág. 43. 
y características, aunque pronto comprobarán que la organización era por lo menos incipiente, dado que sólo pudieron encontrar tres hondas en manos de los supuestos conjurados.

Los indios pretendían tomar el poder y se les acusa de haber hecho labrar insignias "de las que usaba el Inga" y otra planchita con las armas que el Rey les había otorgado a los cañaris del valle y que las usaron en tiempos de guerras y cuando acompañan al corregidor. ${ }^{31}$ No se trata entonces de una simple revuelta para aliviar las condiciones opresivas del modelo colonial. La propuesta incluye directamente un reemplazo de los titulares del poder. En la matanza participarían también los mulatos y los negros. La propuesta incluía además la exterminación de los españoles, religiosos y mestizos. En la averiguación se involucra a los hijos del curaca de Quispicanchis. Se llamaban Juan y Pedro Atacuallpa y habían viajado a Lima a litigar, pretendiendo que se les reconocieran los privilegios propios de su condición noble, probablemente por alguna filiación Inca, como lo sugiere Pease. Sus reclamaciones están, además, vinculadas a los apremios que soportan los indios por parte de los corregidores y a los abusos que se cometían en las mitas, o sea que una vez más encontramos mezclados los intereses individuales, los colectivos y las reivindicaciones utópicas simbolizadas por la insignia del Inca. Con motivo de la denuncia de un arriero que les acompañaba fueron interrogados acerca de sus actividades en Lima, porque el arriero

“...oyó en el baratillo a los dichos hijos del curaca de Quiquixana que habían oydo que habían de herrar a los yndios y los havían de vender y que lo habían oydo junto a las Casas del Cabildo de Lima y que no saben si lo oyeron a los españoles o a yndios... fueron interrogados sobre las versiones que corrían entre los indios diciendo que los españoles ... habían de herrar a los indios y los habían de vender y que lo habían oído junto a las casas del Cabildo de Lima...”. ${ }^{32}$

Todos estos discursos son similares a aquellos con los que Pedro Bohorques buscaba sumar adeptos a su causa en sus incursiones fuera del valle Calchaquí . Por cierto, no es necesario, sino más bien improbable que hayan sido inspirados por Bohorques desde la cárcel, ya que eran ideas que corrían por los Andes y que sustentaban temores y hasta revueltas en varios sitios. Es más, Pease recuerda que en los sucesos en Cajatambo se consigna el rumor que corría entre los indios de que se había dado "Cédula para

31 ACM-HEC, f. 23R, citado por Pease: "Mesianismo andino e identidad étnica...”, pág. 64.

32 Ibídem, f. $13 \mathrm{v}$. 
que fuesen reducidos a esclavitud, quitándoles sus caciques y gobernadores". Incluso pudieron producirse temblores en Cuenca, ${ }^{33} \mathrm{y}$ en Quito con los disturbios provocados por el corregidor don Alonso de Arenas y Florencia Inga. ${ }^{34}$ Por todo ello es posible que Pedro Bohorques se hubiera identificado con el programa y, por qué no, que haya visto en este movimiento la posibilidad de conseguir su liberación. Es difícil saber si tenía algún predicamento entre los indígenas de Lima y el número de curacas que podrían haber contactado desde su prisión. Lo cierto es que las autoridades consideraron que su vinculación con este movimiento era suficiente como para justificar que finalmente se pusiera en obra su postergada ejecución. De todas maneras, las fechas son un tanto inciertas. La sentencia, publicada por Lozano, tiene fecha del 3 de diciembre de 1666 y a causa de los temores que despertó la conjuración, que también le costó la vida a ocho curacas de Lima, Bohorques fue ejecutado el 3 de enero de $1667 .{ }^{35}$ Los curacas también fueron ahorcados el día 21 de ese mes; se les cortaron las cabezas y sus cuerpos fueron hechos cuartos. El resto de los conjurados fue enviado a galeras. ${ }^{36}$

\section{Revueltas y rebeliones de españoles, criollos, mestizos $e$ indios}

Uno de los casos más conocido fue el de los combates entre "vicuñas y vascongados" que ensangrentaron Potosí a comienzos del siglo XVII. Estas rivalidades reflejan la competencia entre peninsulares ricos, y los criollos y andaluces (los "vicuñas"), que pretendían acceder a las ricas vetas del cerro. La competencia entre ambos grupos tuvo una historia larga y tortuosa, pero aunque el móvil económico focaliza el conflicto, la disputa por espacios de poder no estaba por cierto ajena en estas competencias, y es un buen caso para ilustrar los problemas del criollismo.

33 En Chacón, Juan: Historia del Corregimiento de Cuenca (1557-1777), Quito, 1990, pág. 307; citado por Domínguez: "Mestizo, Rebels against the King in the colonial Andes..." (ms).

34 Estudiado por Klumpp, Kathleen: "El retorno del Inga: una expresión ecuatoriana de la ideología mesiánica andina”, Cuadernos de Historia y Arqueología, vol. XXIX, n. o 41, Guayaquil, 1974, págs. 99-135. Citado entre otra bibliografía pertinente al tema por Domínguez: "Mestizo, Rebels against the King in the colonial Andes...".

35 Mugaburu, Joseph y Francisco de: Diario de Lima (1640-1694), Lima, 1935, pág. 84

36 Los autos referidos a esta rebelión se encuentran en AGI, Lima 258 y AGI, Lima 171. Carta del virrey conde de Lemos a Garay Secadura, Lima, 31 de diciembre de 1667, citas tomadas de Lohmann Villena: El conde de Lemos..., pág. 92. 
Pero más interesante por su amplitud social fueron los sucesos de Laicacota, porque permiten renovar el enfoque sobre conflictos que enfrentan a peninsulares de distinto origen regional, a criollos, indios y mestizos y ejemplifica mejor la hipótesis de que en la raíz de los problemas se encuentra, además de la competencia por recursos, la heterogeneidad de la población colonial y sus fluctuantes adscripciones. El detonante de los sucesos de Puno (más precisamente Laicacota) y La Paz, entre 1661 y 1668, fue la competencia entre bandos de mineros, complicado con problemas de defraudaciones fiscales. En este caso, además, hubo caciques que participaron del lado de las autoridades, incluso aportando cuantiosos recursos como Bartolomé Tupa Hallicalla. ${ }^{37}$ En esta rebelión el poder central fue en ciertos momentos cuestionado, por lo que provocó finalmente una fuerte represión encabezada por el virrey conde de Lemos. ${ }^{38}$

Se pueden considerar dos momentos álgidos: 1661-63 y 1665-68. En el primero se enfrentan dos bandos, parcialmente diferenciados por su origen étnico y/o social. Uno de ellos encabezado por los hermanos José y Gaspar Salcedo, andaluces, que se habían enriquecido en muy poco tiempo de manera desmesurada gracias a la explotación de las minas de Laicacota . Convocan principalmente a peninsulares, llamados "criollos de España", entre los que incluyen a los vizcaínos y a nacidos en la tierra, los "criollos de este Reino". ${ }^{39}$ El otro bando, que es expulsado de sus minas por los primeros y que provocan asaltos hasta llegar al combate abierto, está integrado por unos 500 "mestizos y criollos" y 150 indios reclutados entre los trabajadores asalariados de las minas. En esta fase el bando de los Salcedo derrota a los "mestizos y criollos", y éstos a su vez matan a un corregidor en La Paz, a la voz de "Viva el Rey, muera el mal gobierno". ${ }^{40}$

Acosta hace un interesante estudio de las categorías sociales que aparecen y del valor subjetivo de las mismas. En el bando vencedor hay sevi-

37 Glave, Miguel: Trajinantes. Caminos indígenas en la sociedad colonial. Siglos XVI/XVII, Lima, 1989, pág. 296.

38 Gran parte de la información sobre esta rebelión proviene de los libros de Lohmann Villena: El conde de Lemos...; Basadre, Jorge: El Conde de Lemos y su tiempo, Lima, 1945.

39 Acosta, Antonio: "Conflictos sociales y políticos en el sur peruano. (Puna, La Paz, Laicacota 1660-1668)”, en Primeras Jornadas de Andalucía y América, La Rábida, Huelva, 1981, pág. 296. Este tema ha sido abordado en forma similar por Thierry Saignes y Thèrése Bouysse-Casagne: "Dos confundidas identidades: mestizos y criollos del siglo XVII", en Tomoeda, H. y L. Millones: 500 años de mestizaje en los Andes. Senri Ethnological Studies. 33, págs. 14-36. Osaka, Japan, National Museum of Ethnology.

40 Crespo Rodas, Alberto, Mariano B. Gumucio y José de Mesa: La ciudad de La Paz, La Paz, 1989. 
llanos, como los Salcedo, vizcaínos y vascos, y el resto "naturales de estas provincias" o "criollos de este Reino", mostrando que podían existir alianzas entre peninsulares y criollos si los intereses económicos así lo aconsejaban. Gaspar Salcedo se distinguía sin embargo del resto de los de su clase por sus vestimentas provocativas, y como dice Lohmann Villena, "en su atavio traía el hábito de los que en el Perú tenían la profesión de aventureros [...] Gastaba, además de espada y daga, dos pistolas pendientes al descubierto del cinto" ${ }^{41}$ En el bando de los rebeldes, según los discursos contenidos en distintos documentos que se ocuparon del asunto, hay "criollos del común", "gente criolla mestiza", "mestizos", "criollos y mestizos criollos", pero es notorio que no hay peninsulares. Por cierto que estas categorías no eran rígidas y había un fuerte componente de subjetividad para aplicarlas. Si bien a veces las atribuciones - como la que hace un artesano platero que es interrogado- ${ }^{42}$ fueron expresadas en términos raciales (rasgos físicos), no hay duda de que existían componentes de marginación social sumados a descontentos por exclusiones político-económicas de diverso rango, ya sean éstas permanentes o coyunturales, que incidían en los discursos clasificatorios. Nicanor Domínguez, en sus trabajos ya citados, está prestando especial atención a estos componentes étnico-sociales y culturales que intervienen en estos acontecimientos y en mi opinión su trabajo, siguiendo en parte la línea inaugurada por Acosta, promete renovar las investigaciones sobre esta rebelión. Por ejemplo, uno y otro bando incluían personas acaudaladas, pero en los escritos del bando de los Salcedo y de las autoridades, durante la primera fase de la rebelión, se hablaba de los otros en términos de "delincuentes y forajidos". El problema es complejo, y es peligroso hacer generalizaciones apresuradas. Lo que se observa es una intrincada red de factores que podían determinar el lugar que cada individuo ocupaba en esa sociedad que se caracterizaba por una gran movilidad, tanto hacia arriba como hacia abajo.

Con respecto a los indígenas que participaron directa o indirectamente en esta rebelión de La Paz y de Puno, se encuentran dos situaciones diferentes: los forasteros reclutados en las minas y que fueron utilizados en los combates y los indios de comunidad. Nicanor Domínguez sostiene que muchos de los llamados mestizos eran en realidad indígenas desarraigados de sus pueblos y por lo tanto con intereses diferentes a los de comunidad.

41 Lohmann Villena: El conde de Lemos..., pág. 153.

42 Acosta: "Conflictos sociales y políticos..., pág. 36. 
Tanto es así que los rebeldes les propusieron a los del pueblo de Zepita que los apoyasen

\footnotetext{
"siguiéndoles con todos sus indios y matando a los españoles, [que] no tendrían que pagar tasas ni tributos, [y] no les mandarían nada y quedarían libres", ${ }^{43}$
}

pero el curaca de Zepita rechaza la propuesta, declarándose fiel vasallo del Rey, por lo que es ejecutado por los rebeldes. El discurso de los amotinados tiene claras intenciones de rebeldía contra la autoridad y reclamo de alianza interétnica. Pero la situación resultó ser suficientemente confusa como para que fracasara.

En la segunda fase, 1665-66, las motivaciones fueron similares, pero cambian las alianzas, y en opinión de Antonio Acosta, aquí es más evidente que están más ligadas a los intereses económicos que a los orígenes de cada grupo. Los anteriores aliados (en realidad aliados conyunturales) desnudan odios y rivalidades por la explotación de las vetas más ricas, que enfrentaban a vascos y vizcaínos contra andaluces. El 8 de marzo de 1666, los Salcedo al mando de 600 hombres e indios de servicio, atacan Laicacota y toman posesión del asiento minero al grito de "Muera el mal gobierno, viva el Rey y el Papa". Algunas autoridades apoyan a Salcedo, entre ellos el obispo de Arequipa, pero otras están en su contra. Del lado oficial, el temor se expresa diciendo que los rebeldes eran "mestizos y gente suelta". Los vizcaínos a su vez moteaban a los andaluces de "moriscos" y a los criollos de "gentiles". ${ }^{44} \mathrm{O}$ sea, la estigmatización socio-étnica que diaboliza al enemigo.

El nuevo virrey conde de Lemos decidió emprender personalmente una campaña para someter a los conjurados en julio de 1668. José Salcedo, que anteriormente había sido nombrado justicia mayor del distrito de Paucarcolla, con sede en Laicacota, organizó la defensa del pueblo. Pero ante el avance de las tropas del virrey, los conjurados abandonaron la plaza. Los principales cabecillas fueron condenados y ejecutados, entre ellos el propio José Salcedo, pero su hermano Gaspar, preso en el Lima, aunque también condenado a pena capital, fue finalmente indultado por el Consejo de Indias. Además, se le permitió recuperar sus propiedades y uno de sus hijos, incluso, recibió título de marqués y el hábito de una orden militar. ${ }^{45}$

43 Ibídem; documento citado en pág. 39.

44 Lohmann Villena: El conde de Lemos..., pág. 170

45 Ibídem, pág. 224. 
Por cierto, esta rebelión que comenzó como un conflicto de intereses terminó transformándose en resistencia y traición a la autoridad real. Basadre sostiene que se trata de un conflicto entre la autoridad política y el poder económico y desliza que también es una rivalidad entre la nobleza de sangre y los hombres de reciente ascenso social. Por su parte, los extensos capítulos que Lohmann Villena dedica a Laicacota también revelan que aunque las intenciones de separatismo nunca pasaron de proclamas aisladas, las intrigas y alianzas podían conducir a una franca sedición. Al finalizar la contienda, el conde de Lemos escribe al Rey diciendo que había reconquistado el Perú, porque lo había encontrado a punto de perderse.

Los trabajos de Acosta y de Domínguez han puesto atención en la composición social de los actores, y en particular en la presencia de mestizos, muchos de ellos, tal vez, indios desarraigados de sus comunidades, circunstancia que obliga a mirar al revés de la trama. Como envés de algunos de los trabajos de Thierry Saignes, ${ }^{46}$ que centró su atención en las estrategias positivas de las comunidades indígenas, esta rebelión descubre la gran masa de desarraigados (temporarios o permanentes) y mestizos que buscaban soluciones individuales haciendo frente y/o incorporándose al sistema colonial. Y que a diferencia de las comunidades que optaron en este siglo por una resistencia pasiva o diversas modalidades del así llamado "pacto colonial", las estrategias individuales podían conducir también a la rebelión contra "el mal gobierno".

\section{Reflexiones finales}

Las rebeliones y revueltas cuyos participantes pertenecen al sector de origen europeo y a los mestizos, merecen mayor discusión y para ello es imprescindible recurrir a las nociones de solidaridad social, ética cristiana en sus diversas interpretaciones y en general a los problemas derivados de las relaciones sociales. Más allá del aparato institucional, económico y legal en el que se encontraban insertos, lo que revelan muchos de estos conflictos es el problema de la insolidaridad social y de la moral laxa predominante en este particular contexto colonial y que lamentablemente no se manifiestan sólo en estos casos extremos de revueltas armadas. Los deba-

46 Saignes: "Las etnias de Charcas frente al sistema colonial..." y "Algún día todo se andará. Los movimientos étnicos...". 
tes jurídicos, casi cotidianos, y la corrupción generalizada en todos los niveles sociales deberían ser objeto de mayor atención que la prestada hasta el momento.

Hay conflictos con la Corona o intersectoriales, pero parece no haber existido un consenso social fuerte para defender los derechos y libertades comunes por encima de los individuales o de los grupos de presión. Esto no significa que el concepto de bien común estuviera ausente. En la legislación y en sinnúmero de documentos colectivos o individuales, esta preocupación se encuentra en forma reiterada. Sin embargo, no parece haber sido plenamente asumida por la población en sus prácticas políticas ni en las cotidianas. La solidaridad social era insuficiente y no apta para construir mecanismos de premios y castigos, iguales para todos, al menos al nivel de aceptación/rechazo dentro de la propia sociedad. Durkheim ${ }^{47}$ a diferencia de Kant que propone que las reglas constituyen un imperativo categórico, sostiene que es imposible que un acto se cumpla solo porque es ordenado, abstrayéndolo de su contenido. Es necesario que se incorpore a la sensibilidad de los individuos, que sea deseable, condición que no parece haberse cumplido si dejamos de lado los discursos y consideramos la conducta cotidiana. Lo que más sorprende, como lo he dicho en otros trabajos ${ }^{48}$ es que las mismas prácticas insolidarias rigen tanto en las relaciones dominante/dominado como en las horizontales entre los miembros del sector dominante.

Debemos preguntarnos cuánto incide este problema en el desarrollo de una sociedad colonial disgregada sectorialmente, que se aprovechaba de la debilidad del Estado y del silencio cómplice de la Iglesia, que toleraba una vinculación con Dios más formal o ritualista que gobernada por una fe profunda y cotidianamente consciente. Al carecer de una sólida amalgama ética y de capacidad para percibir la delgadez del cemento que regulaba la convivencia, ésta fue una sociedad que no pudo defenderse, como un solo cuerpo de comunidad, de las apetencias, de las pasiones y las desviaciones de sus miembros.

Y a mi juicio, la raíz de todo esto se encuentra en las dificultades para construir una identidad bien consolidada. La multietnicidad, mirada desde varios ángulos, presenta claros contrastes: indio/blanco; indio/negro; blanco/negro. Entre los peninsulares la propia ambigüedad nacida de su traumático desarraigo, con solidaridades divididas entre su país de origen y el

47 Durkheim, Emile: Sociologie et Philosophie, Paris, 1967.

48 Lorandi, Ana María "Facciones, poder y ética en el siglo XVIII", (ms) 1998. 
de adopción y, finalmente, la región específica en la cual nacieron, andaluces, vascongados, extremeños, castellanos, etc. Hay diferencias en los momentos y condiciones de la emigración; el recién llegado versus el ya establecido. A esto se suma el desfase generacional peninsular/criollo que se fue acrecentando con el transcurso del tiempo. Todo confluía para que ante tanta diversidad humana, y tanta variedad de las historias individuales y familiares, ni aún en aquellas zonas con menor movilidad o más conservadoras lograran construir una identidad que permitiera desarrollar mecanismos de premios y castigos coherentes, consensuados y deseables. 